\title{
Everolimus ist auch nach fünf Jahren noch wirksam
}

Fragestellung: Bleibt die Wirkung von Everolimus bei Patienten mit tuberöser Sklerose und SEGA im längeren Verlauf erhalten?

Hintergrund: Sogenannte subependymale Riesenzellastrozytome (subependymal giant cell astrocytoma, SEGA) gehören $\mathrm{zu}$ den typischen Manifestationsformen der tuberösen Sklerose, einer genetischen Erkrankung, die durch Mutationen in den Genen TSC1 (Hamartin) oder TSC2 (Tuberin) verursacht wird. Beide Mutationen führen zu einer Aktivierung des mTOR(mammalian-target-of-rapamycin-)Signalwegs. Folgerichtig wurden Inhibitoren von mTOR als Therapie behandlungsbedürftiger Patienten mit SEGA etabliert.

Patienten und Methodik: Patienten im Alter von mindestens drei Jahren mit gesicherter tuberöser Sklerose und progredienten SEGA wurden mit Everolimus in einer Startdosis von $3 \mathrm{mg} /$ $\mathrm{m}^{2}$ behandelt. Der primäre Endpunkt war die Reduktion des Tumorvolumens.

Ergebnisse: Zum Cut-off des 28. Januar 2014 hatten 22 von den initial 28 Patienten die Studie abgeschlossen. Die mediane Behandlungsdauer betrug 67,8 Monate (Spannweite: 4,7-83,2 Monate). Von 23 Patienten zeigten zwölf $(52,2 \%)$ beziehungsweise 14 Patienten (60,9\%)

Franz DN, Agricola K, Mays M et al. Everolimus for subependymal giant cell astrocytoma: 5 -year final analysis. Ann Neurol 2015; 78: 929-38
Volumenreduktionen von $50 \%$ beziehungsweise $30 \%$ nach 60 Monaten Behandlung im Vergleich zum Studieneinschluss. Nach $60 \mathrm{Mo-}$ naten litten nur noch zwei

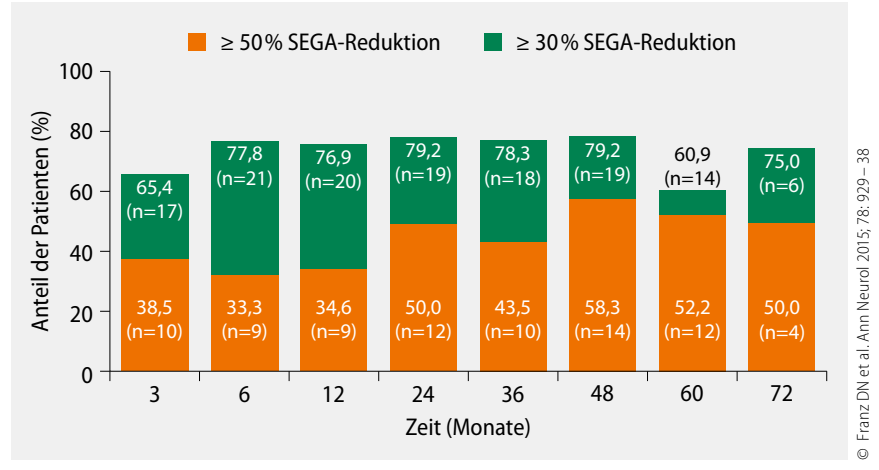

1 Volumenreduktion der primären subependymalen Riesenzellastrozytome (SEGA) im Studienverlauf gegenüber Baseline (dargestellt sind die jeweiligen jährlichen Werte nach zwölf Monaten Behandlung).

von 18 Patienten (11,1\%) an täglichen Anfällen im Vergleich zu sieben von 26 Patienten (26,9\%) bei Studieneinschluss.

Die wichtigsten im Studienzeitruam beobachteten Nebenwirkungen waren Atemwegsinfektionen und Stomatitis. Keiner der Patienten brach die Therapie aufgrund von Nebenwirkungen $\mathrm{ab}$.

Schlussfolgerungen: Die Autoren folgern aus den vorliegenden Studiendaten, dass die Behandlung mit Everolimus über einen Zeitraum von fünf Jahren zu einer befriedigenden Tumorkontrolle führt. Diese ging mit einem relativ günstigen Nebenwirkungsprofil einher, ohne dass neue Nebenwirkungen oder Sicherheitsbedenken auftraten.

\section{- Kommentar von Michael Weller, Zürich, Schweiz}

\section{mTOR-Hemmung als Therapiekonzept etabliert}

Die Einführung von mTOR-Inhibitoren in die Therapie der SEGA bei tuberöser Sklerose gehört zu den bisher wenigen Beispielen erfolgreicher zielgerichteter Therapie im Bereich der Neuroonkologie, die auf einem besseren Verständnis der molekularen Pathogenese von Tumoren beruht. Wegen der zentralen Bedeutung des mTOR-Signalwegs und des oft jugendlichen Alters der betroffenen Patienten standen Sicherheitsbedenken von Anfang an im Mittelpunkt der Betrachtung bei Einführung dieser neuen Therapie. Die jetzt vorliegenden Daten weisen darauf hin, dass auch im längerfristigen Verlauf über fünf Jahre mit mTOR-Inhibition nicht nur eine gute Tumorkontrolle erreicht wird, sondern dass das Nebenwirkungsprofil günstig bleibt und das Risiko von Nebenwirkungen im längeren Verlauf eher abnimmt. In zukünftigen Untersuchun- gen wird es interessant sein, genauer zu untersuchen, welchen Einfluss diese Therapie auf die Epilepsie und die kognitive Entwicklung betroffener Kinder hat.

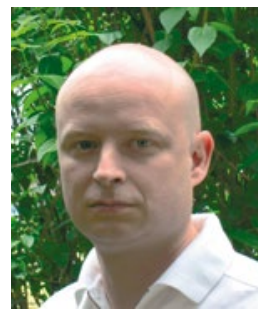

Prof. Dr. med. Michael Weller, Zürich/Schweiz

Direktor der Klinik für Neurologie,

Universitätsspital Zürich

E-Mail:michael.weller@usz.ch 